\title{
CORTISONE AND ITS ANALOGUES IN ENDOCRINOLOGY
}

\author{
By R. I. S. BAyliss, M.A., M.D., F.R.C.P. \\ Physician, Westminster Hospital, London
}

There can be no doubt that cortisone and its analogues have revolutionized the treatment, and to a lesser extent the diagnosis, of endocrine diseases during the last decade. Although available through the pharmaceutical houses in a wide variety of different formulations to meet particular needs, these steroids can be classified into three main groups according to their influence on salt and water and on carbohydrate metabolism:

(a) Prednisone and prednisolone have for practical purposes in clinical endocrinology no effect on salt and water metabolism, although on a weight for weight basis they are some four or five times more potent than cortisone in their anti-inflammatory and liver glycogen-deposition action. Their failure to influence sodium metabolism makes them of little value in the treatment of endocrine conditions when there is adrenal insufficiency, but enhances their usefulness in the treatment of certain general medical conditions, such as the collagen disorders (see page 322 ).

(b) Cortisone and hydrocortisone influence both carbohydrate metabolism and, to a lesser extent, the renal excretion of sodium. This makes them particularly valuable as substitution agents in patients with adrenal insufficiency. Weight for weight, cortisone is about four-fifths as potent as hydrocortisone and is converted in the body to hydrocortisone before exerting any physiological action. Cortisone and hydrocortisone are absorbed from the gastro-intestinal tract within an hour, whether administered as the free alcohol or as the acetate ester. Given by intramuscular injection absorption is much slower and more prolonged, and this route is not satisfactory when a rapid response is needed, as in acute adrenal insufficiency. For this purpose water-soluble preparations of hydrocortisone (the free alcohol dissolved in ethanol and diluted with saline, or the hemisuccinate ester) are available for intravenous use.

(c) Halogenated derivatives of (a) and (b) have been synthesized and the fluorinated compounds are more potent than those in which chlorine or bromine has been substituted: These sub- stances have an intense sodium-retaining action and used in a dosage which does not cause oedema or hypertension have a less striking effect on carbohydrate or protein metabolism. They suppress the pituitary secretion of ACTH, which makes them useful in certain diagnostic situations, but it is their sodium-retaining action which is of great clinical value. The only compound of this group commercially available is $9-a$-fluorohydrocortisone in tablets containing I mg. or $0.1 \mathrm{mg}$. and this has supplanted deoxycortisone acetate or trimethyl acetate in the treatment of Addison's disease. Other substances in this group which are currently under investigation are $\triangle^{1}$-fluorohydrocortisone (Bartter, 1956; Bayliss, 1957a) and 2-methyl-9afluorohydrocortisone (Liddle and Richards, 1956; Gurling, Gore and Baron, 1957). Both have a greater sodium-retaining action than 9a-fluorohydrocortisone and weight for weight a greater suppressive effect on the pituitary secretion of ACTH.

\section{Therapeutic Uses \\ Chronic Adrenal Insufficiency}

In Addison's disease, or after bilateral adrenalectomy, oral cortisone is the mainstay of substitution therapy (Fourman and Horler, 1954). Most totally adrenalectomized patients can be maintained on $50 \mathrm{mg}$. a day, which should be given as $12.5 \mathrm{mg}$. six-hourly. Patients with Addison's disease need 12.5 to $50 \mathrm{mg}$. daily, depending on the severity of the condition and the completeness of adrenal destruction. In these ' physiological' amounts there is no question of cortsone aggravating a tuberculous infection if this is the cause of the adrenal insufficiency. These quantities are the requirement of an adult leading an ordinary sedentary life without unusual exertion. Manual workers may require more, and each patient should have an emergency supply of several grammes in case they become involved in an accident, and given instructions about the increased need for glucocorticoid hormones during an acute infection, painful dental treatment and other physically or 


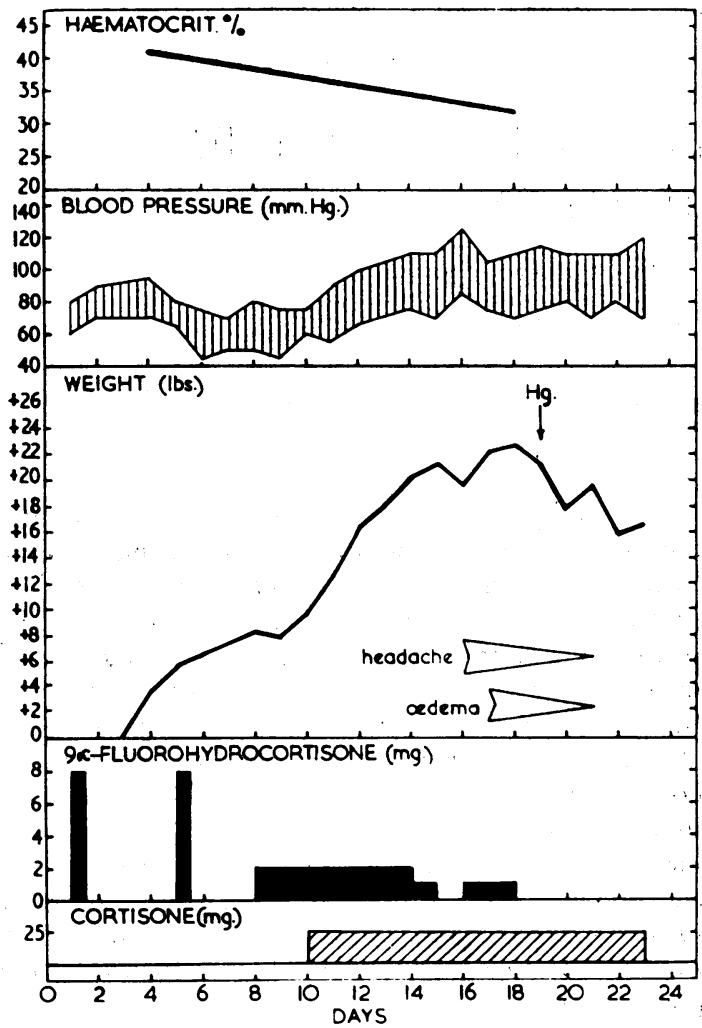

FIG. I.-The response in an Addisonian man aged $5^{8}$ to $0 \alpha$-fluorohydrocortisone. When first seen at home $8 \mathrm{mg}$. were given with a remarkable clinical improvement. He was then admitted to hospital to confirm the diagnosis, but relapsed into a pre-crisis state on the fifth day and was given another $8 \mathrm{mg}$. Two mg. fluorohydrocortisone, and later the addition of $25 \mathrm{mg}$. cortisone, caused an excessive increase in weight due to salt and water retention. On the fifteenth day his weight had increased $20 \mathrm{lb}$., the jugular venous pressure was raised and he complained of a headache. The next day he had oedema of the ankles and orthopnoea due to pulmonary congestion. Stopping the fluorohydrocortisone and giving an injection of mersalyl $(\mathrm{Hg})$ induced a marked diuresis and loss of weight. Subsequently he has remained well on $37.5 \mathrm{mg}$. cortisone a day and $0.5 \mathrm{mg}$. fluorohydrocortisone every third day. The cortisone was increased from 25 to $50 \mathrm{mg}$. because on the lower dosage his blood urea rose to $60 \mathrm{mg}$. per $100 \mathrm{ml}$.

mentally traumatic episodes. Under conditions of maximum stress, such as a major operation, 400 mg. a day are required to prevent adrenal insufficiency and proportionately smaller amounts in less serious situations.

The exact maintenance dosage is best judged by the patient's sense of well-being, and there is a striking improvement in their energy, mental faculties and stamina. An excessive appetite and marked gain of weight indicate over-dosage. In the absence of renal disease an elevated blood urea usually indicates a reduced glomerular filtration rate anfof insufficient glucocorticoid replacement. Although some (Beck and Montgomery, 1956) have main $\frac{0}{3}$ tained that cortisone alone is adequate replace ment in adrenal insufficiency, it has been my experience and that of others (Nabarro and Walker 1957) that, unless an additional hormone withe greater mineralocorticoid activity is given, clinicad manifestations of sodium depletion or biochemica\$ abnormalities (a low serum sodium level and some $\frac{\bar{\omega}}{\frac{\mathrm{c}}{\mathrm{s}}}$ times also hypochloraemia and hyperkalaemia $\$$ may occur, even though supplements of sodiung chloride are given. For this reason routine estima $=$ tion of the blood urea and serum sodium, chloride and potassium levels is necessary. Correction of hypotension or hyponatraemia is best achieved witl 9 a-fluorohydrocortisone by mouth. The amoun given must be sufficient to achieve normal serum electrolyte levels and not so great as to inducki oedema or hypertension (Fig. I), although itw should be remembered that the 'normal' blood pressure of elderly patients may be greater than the् statutory $120 / 80 \mathrm{~mm}$. $\mathrm{Hg}$, and these patients wils feel better when the blood pressure is maintained at 140 to $150 / 90 \mathrm{~mm}$. Hg. Although some workers have used a compound tablet containing bot cortisone and fluorohydrocortisone (Leith an Beck, 1957), greater flexibility is obtained if the two steroids are given separately. Fluorohyd 0 잉 cortisone is slow in producing its effect and loig lasting, so that adjustments in dosage should 9 Q made gradually. The individual dose varies, $\overrightarrow{b u t}$ most patients require $0.1 \mathrm{mg}$. every day or of alternate days and some are satisfactorily con trolled with $0.5 \mathrm{mg}$. every third day. A carefư watch must be kept for the development of oedem or hypertension. Usually these occur together, although Owen and his colleagues (1957), using doses that would now be considered too large. noted hypertension without oedema in some patients and oedema without hypertension ing others.

It is now our practice to start replacemenio therapy in chronic adrenal insufficiency with cortisone and later, after one to two weeks, to add fluorohydrocortisone. Often the addition of the potent mineralocorticoid requires an adjustment in the dose of cortisone (Leith and Beck, 1957) because to some extent cortisone and fluorohydrog cortisone are mutually antagonistic in their actions In an adrenalectomized patient replacemento therapy with fluorohydrocortisone alone readily induces oedema; if cortisone is then given and the dose of fluorohydrocortisone maintained unalterec the oedema usually subsides (Bayliss, 1957b) Thus, in controlling chronic adrenal insufficiency a nice balance between cortisone and fluorohydrocortisone must be achieved. On this regimen

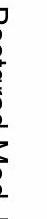


is not necessary to give additional supplements of sodium chloride.

\section{Acute Adrenal Insufficiency}

Depending on the severity of the patient's condition, treatment should be intravenous or by mouth. It is a common mistake to think that an intramuscular injection of cortisone or hydrocortisone will have a more rapid effect than oral treatment. Usually the patient is dehydrated, hypotensive and may also be hypoglycaemic, and the fact that he is vomiting demands intravenous treatment. An infusion of $500 \mathrm{ml}$. 5 per cent. glucose in saline is set up and $100 \mathrm{mg}$. hydrocortisone free-alcohol dissolved in 50 per cent. ethanol added to the bottle, or $134 \mathrm{mg}$. hydrocortisone hemisuccinate dissolved in $10 \mathrm{ml}$. saline injected into the tubing. After two hours the same amount of steroid is given with I 1 . of glucose saline. During the first 24 hours 2.5 l. of fluid and $400 \mathrm{mg}$. hydrocortisone should be infused. If hypotension is not corrected quickly, 2 to $4 \mathrm{mg}$. nor-adrenaline are added to each bottle of infusion. As soon as clinical improvement allows and vomiting has stopped, cortisone and fluorohydrocortisone are given orally as in chronic adrenal insufficiency. Where the acute adrenal failure is due to a fulminating infection (Waterhouse-Friderichsen syndrome) the appropriate antibiotic must be given in maximum dosage.

During bilateral adrenalectomy a depot of cortisone is provided by injecting intramuscularly $\mathrm{r} 00$ mg. cortisone acetate on the night before and again two hours before the operation. During the operation and for the next 24 hours an infusion of 21 . of 5 per cent. glucose is given containing 300 to $400 \mathrm{mg}$. hydrocortisone. During the next 24 hours two intramuscular injections of roo $\mathrm{mg}$. cortisone are given and then $50 \mathrm{mg}$. cortisone six-hourly by mouth for 48 hours. The dosage is gradually reduced over the next seven days until maintenance therapy with $12.5 \mathrm{mg}$. six-hourly is being given. At this time fluorohydrocortisone is added. As in acute adrenal insufficiency, nor-adrenaline is infused over the operation period if the systolic blood pressure falls below $100 \mathrm{~mm}$. $\mathrm{Hg}$.

\section{Panhypopituitarism}

Although the clinical picture of panhypopituitarism is usually dominated by the manifestations of thyroid and gonadal failure, adrenal insufficiency is a constant accompaniment and may give rise to hypoglycaemic coma. Electrolyte abnormalities and sodium depletion seldom occur as in primary adrenal insufficiency because secretion of aldosterone by the suprarenal cortex continues despite pituitary failure. Treatment with 12.5 mg. cortisone twice daily causes a striking

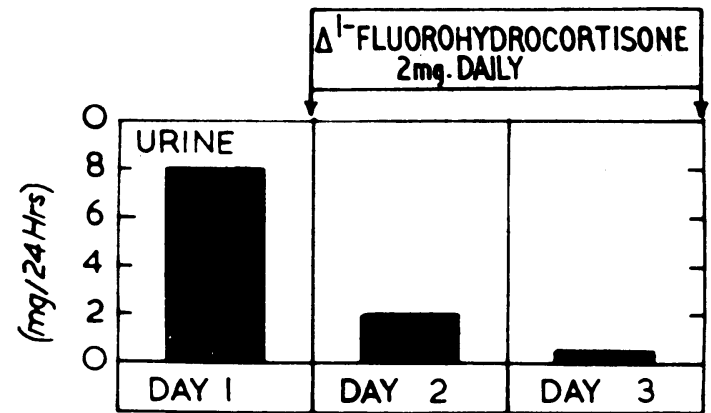

FIG. 2.-Response of I7-ketosteroid excretion in a female aged two years with congenital adrenal hyperplasia to $2 \mathrm{mg}$. a day of $\triangle^{1}$-fluorohydrocortisone. The grossly raised excretion of $8 \mathrm{mg}$. on day I fell promptly to less than $0.5 \mathrm{mg}$. after 48 hours.

improvement in the patient's mental and physical lethargy and safely allows the introduction of thyroxine and testosterone as additional substitution therapy (Sheehan and Summers, 1954; Beck and Montgomery, 1957).

\section{Adrenogenital Syndrome}

This syndrome, characterized by excessive adrenal secretion of androgens and high urinary 17-ketosteroid excretion, is manifest by pseudohermaphroditism in females and macrogenitosomia praecox in males. The condition is due to an enzymic defect in the adrenal cortex which prevents the normal biosynthesis of hydrocortisone, and this in turn leads to increased pituitary secretion of ACTH. Wilkins and his associates (195I) were the first to show that the condition could be treated satisfactorily by giving cortisone, which suppressed the pituitary and caused a fall in the adrenal secretion of androgens. The treatment is controlled by inducing sufficient pituitary suppression to reduce the urinary excretion of 17 -ketosteroids to a normal level for the age of the patient.

On a weight for weight basis the pituitary suppressive action of the following steroids is in the order $9^{a}$-fluorohydrocortisone, prednisone, hydrocortisone and cortisone (Kupperman et al., I955). $\triangle^{1}$-fluorohydrocortisone is even more potent (Fig. 2), but neither of the fluorinated compounds can be used for prolonged treatment because they so readily induce oedema and hypertension (Kupperman et al., 1955; Owen et al., 1957). Prednisone and prednisolone are more effective, weight for weight, than either cortisone or hydrocortisone orally, and being given in smaller amounts they themselves make a negligible contribution to the urinary excretion of 17 -ketosteroids. If large amounts of cortisone or hydrocortisone are required, it becomes difficult to judge whether the desired degree of pituitary suppression has been 
achieved because the exogenous steroid adds to the 17-ketosteroid excretion. For reasons of convenience oral treatment with prednisone or prednisolone is probably the method of choice (Spence et al., 1956), but the pituitary suppression will be more intermittent than that achieved by the less convenient intramuscular injections of cortisone or hydrocortisone. However, an intramuscular injection of microcrystalline cortisone once monthly (Prader, 1953) or of hydrocortisone acetate once a fortnight (Segaloff et al., 1955) may be effective.

\section{Thyroid Disease}

Cortisone has been recommended for the relief of symptoms in acute non-suppurative thyroiditis (Werner, 1953). The aetiology of this curious condition is still uncertain, although the possibility of infection with the mumps virus or an auto-immunity reaction has recently been suggested. Cortisone and prednisone are effective, probably as a result of their non-specific antiinflammatory action, but anti-thyroid drugs, such as Neomercazole, are also effective and are probably the treatment of choice, although steroids provide more immediate relief of the symptoms.

Cortisone or prednisone may, in some cases, be of value in patients with thyrotoxic exophthalmos and ophthalmoplegia. Those that appear to benefit most are patients with marked chemosis in whom the exophthalmos is of recent origin or has suddenly and rapidly progressed (Lancet, 1955). The dosage of the steroid must be high and prolonged and the dangers of this have to be weighed against the uncertainty of the improvement that may accrue. Nevertheless, in severe, rapidly progressing cases prednisone in large doses ( 40 to $60 \mathrm{mg}$. daily) may be of considerable value.

\section{Stein-Leventhal Syndrome}

This syndrome is characterized by polycystic ovaries, amenorrhoea and hirsutism. Usually the excretion of 17 -ketosteroids is normal. Restoration of menstruation and relief of sterility may be obtained by wedge resection of the ovaries and in a proportion of cases the same results are achieved with small doses of cortisone or prednisone. Unfortunately, neither treatment influences the hirsutism.

\section{Diagnostic Uses Adrenal Insufficiency}

Although the diagnosis of adrenal insufficiency can be confirmed only by showing that the plasima level or urinary excretion of adrenocortical steroids is less than normal, and that there is little or no increase following stimulation with ACTH, a useful preliminary screening test is to study the diuretic response to a water load. The patient empties his bladder at 7 a.m. and then drinks $2 \vec{\theta}$ $\mathrm{ml}$. water per $\mathrm{kg}$. body-weight $(9 \mathrm{ml}$. per lb. body weight). He remains in bed for the next four hour and all the urine passed during this period io collected and measured. A normal person will. void more than 80 per cent. of the water load i $\overrightarrow{\text { के }}$ this time, whereas a patient with adrenal insufficiency will excrete substantially less than $8 \%$ per cent. If such is the case, the test is repeate after 48 hours, but on this occasion $50 \mathrm{mg}$. corti sone are given by mouth four hours before the्ष water is drunk. A normal diuresis is then pre $\$$ sumptive evidence of adrenocortical insufficiency which has been corrected by the orally ad ministered cortisone.

\section{Differentiation of Adrenopathies}

In Cushing's syndrome and the adrenogenitati syndrome it is important to know whether the underlying lesion is hyperplasia, an adenoma or carcinoma of the adrenal cortex. In some cases. palpation of a tumour, tomography after presacraP insufflation of air and a grossly raised 17-keto을 steroid excretion may suggest a carcinoma, but the distinction between an adenoma and hyper plasia may not be possible by these means. In most instances suppression of the pituitary will reduce the excretion of 17 -ketosteroids in teer adrenogenital syndrome and of glucocorticoids ${ }^{\infty}$ Cushing's syndrome when there is hyperplaswa but not when a malignant or benign tumour. is present. Although in high dosage cortisone and hydrocortisone suppress the pituitary secretion of ACTH (Jailer et al., 1954), they contribute sub $\mathbb{D}$ stantially to the urinary output of 17 -ketosteroids and glucocorticoids; therefore the more potent fluorinated compounds are preferred. A daily dose of 5 to 1o $\mathrm{mg}$. $9 a$-fluorohydrocortisone (Cope 1956) or $2 \mathrm{mg}$. $\triangle^{1}$-fluorohydrocortisone (Fig. 2$)$ is sufficient to cause at least temporary depression? of pituitary activity.

\section{Differentiation of Hypercalcaemia}

Hypercalcaemia may occur in a number of con ditions and often there is difficulty in determining the underlying cause. Cortisone may be helpfuts in distinguishing the hypercalcaemia of hyperparathyroidism from that which occurs in a smaln proportion of patients with Boeck's sarcoidosis (Anderson et al., 1954). No patient with Boeck'so sarcoidosis and hypercalcaemia has been reported. as having a low serum inorganic phosphorus level, and this is an important point of differentiationo because in hyperparathyroidism there is hypo-D phosphataemia unless the kidneys are damaged? Furthermore, in Boeck's sarcoidosis 100 to $150 \mathrm{mg} \frac{0}{0}$ cortisone a day for 10 days reduces the serum calcium level and increases the faecal calcium ex- $-\frac{\rho}{8}$ 
cretion. A similar effect may also be observed when cortisone is given to a hypercalcaemic patient with multiple bony metastases if the steroid inhibits the growth of the neoplastic tissue. In hyperparathyroidism, on the other hand, cortisone does not influence the hypercalcaemia.

\section{BIBLIOGRAPHY}

ANDERSON, J., DENT, C. E., HARPER, C., and PHILPOT, G. R. (1954), Lancet, ii, 720.

BARTTER, F. (1956), Metabolism, 5, 369.

BAYLISS, R. I. S. (1957a), Proc. roy. Soc. Med. 5o, 76r.

BAYLISS, R. I. S. (1957b), in 'Modern Trends in Endocrinology,' London, Butterworth.

BECK, R. N., and MONTGOMERY, D. A. D. (1956), Brit. med. F., ii, 921.

COPE, C. L. (1956), Ibid., ii, 193.

FOURMAN, P., and HORLER; A. R. (1954), Lancet, i, 334.
GURLING, K. J., GORE, M. B. R., and BARON, D. N. (1958), 7. Endocr. 16, 304.

JAILER, J. W., GOLD, J. J., and WALLACE, E. Z. (1954), Amer. F. Med., 16, 340.

KUPPERMAN, H. S., BLATT, M. H. G., VESELL M., GAGLIANI, J., WEISBADER, $\dot{H}$., and V'OSBURGH, $L$.' (1955), 7. clin. Endocr., 15, 91 1 .

LANCET (1955), i, 6.

LEITH, W., and BECK, J. C. (1957), Ұ. clin. Endocr., 17, 280.

LIDDLE, G. W. and RICHARDS, J. E. (1956), Sicience, 123, 324. NABARRO, J. D. N., and WALKER, G. (1957), Brit. med. f., OWEN, ${ }^{17}$ j.

EN, J. A., ENGEL, F. L., and WEBSTER, T. B. (1957), F. clin. Endocr., 17, 272.

PRADER, A. (I953), Helv. paediat. Acta 8,386

SEGALOFF, A., GORDON, D., and HORWITT, B. N. (1955), F. Amer. med. Ass., 157, I479.
SPENCE, A. W., JENKINS, J. S., and ROBINSON, A. M. (1956), Brit. med. F., ii, 1348 .

WERNER,' S. C. (1953), $\mathcal{F}$. clin. Endocr., 13, 1332.

WILKINS, L., LEWIS, R. A., KLEIN, R., GARDNER, L. I., CRIGLER, J. F., ROSENBERG, E., and MIGEON, C. J' (195I), Ibid., Ir, I.

\section{ANAESTHETICS \\ (Postgraduate Medicál Journal)}

Price: 3s. 11d. post free

THE MODERN VIEW OF ANAESTHESIA

G. S. W. Organe, M.D., D.A., F.F.A.R.C.S.

THE PRODUCTION OF UNCONSCIOUSNESS

B. G. B. Lucas, D.A., F.F.A.R.C.S.

\section{ANALGESIA}

J. B. Wyman, M.B.E., D.A., F.F.A.R.C.S. MUSCLE RELAXATION IN SURGERY

Angus Smith, F.F.A.R.C.S.

CONTROL OF THE BLOOD PRESSURE AND CONTROLLED HYPOTENSION

C. F. Scurr, M.V.O., D.A., F.F.A.R.C.S.

\section{CHLORPROMAZINE AND ALLIED SUBSTANCES}

John Beard, M.D., D.A., F.F.A.R.C.S., D.C.H.

CONTROLLED HYPOTHERMIA

E. J. Delorme, M.D., F.R.C.S.(C.)

MANAGEMENT OF THE APNOEIC

PATIENT

Ronald Woolmer, D.A., F.F.A.R.C.S.

THE USE OF ANTIDOTES IN

ANAESTHESIA

B. A. Sellick, D.A., F.F.A.R.C.S.

Published by

THE FELLOWSHIP OF POSTGRADUATE MEDICINE

60, Portland Place, London, W.1

Bibliography continued from page 304-Oliver Garrod, M.D., M.R.C.P.

MIGEON, C. J., BERTRAND, J., WALL, P. E., STEMPFEL R. S., and PRYSTORSKY, H. (1957), Ciba Found. Colloq Endocrin., 'Hormones in Blood,' in press, Churchill, London,

MIGEON, C. J., SANDBERG, A. A., DECKER, H. A., SMITH, D. F., PAUL, A. C., and SAMUELS, L. T. (I956), 7. clin. Endocr., 16,1137 and $\mathrm{I} 29 \mathrm{I}$.

MOEHLIG, R. C., and STEINBACH, A. L. (1954), F. Amer. med. Ass., $154,42$.

ORR, R. H., DI RAIMONDO, V., FLANAGAN, M. E., and FORSHẢM, P. H. (1955), Ibid., 15, 763 .

PETERSON, R. E., and WYNGAARDEN, J. B. (1955), f. clin. Invest., 34, 957 .

PETERSON, R. E., and WYNGAARDEN, J. B. (1956), Ibid., 35, 552.

PETERSON, R. E., WYNGAARDEN, J. B., GUERRA, S. L., BRODIE, B. B., and BUNIM, J. J. (1955), Ibid., 34, 1779.

REDDY, W. J. (1954), Metab., 3, 489.
RENOLD, A. E., HAYDER, N. A., REDDY, W. J., GOLDFIEN, A., ST. MÄRC, J. R., and LAIDLAW, J. C. (r955), $A n n$. N.'Y. Acad. Sci., 61, 582.

SAYERS, G. (1950), Physiol. Rev., 30, 241 . SCHIEVE, J. F., SCHEINBURG, P., and WILSON, W. P. (195 I),
f. clin. Invest., 30, 1527 .

SLAUNWHITE, W. R., Jr., and SANDBERG, A. A. (1957), 7. clin. Endocr., 17,395 .

SPERO, G. B., THOMPSON, J., L., MAGERLEIN, B. J. HAUZE, A. R., MURRAY, H. C., SEBEK, O. K., and HOGG, J. A. (1956), F. Amer. chem. Soc., 78, 6214.

VERMEULEN, A. (1956), Acta endocr., 23, I 13.

WADE, A. P., and KELLIE, A. E. (1957), personal communication. WARD, L. E., POLLEY, H. F., SLOCUMB, C. H., HENCH P. S., MASON, H. L., MATTOX, V. R., and POẄER, M. H' (1954), Proc. Mayo Clin., 29, 649.

ZWEICHACH, B. W., SCHORR, E., and BLOCK, M. M. (1953), 